\title{
Song amplitude and body size in birds
}

\author{
Henrik Brumm
}

Received: 26 September 2008 /Revised: 24 February 2009 / Accepted: 25 February 2009/Published online: 13 March 2009

(C) The Author(s) 2009. This article is published with open access at Springerlink.com

\begin{abstract}
Bird song is a sexually selected multidimensional signal. A fundamental question regarding the evolution of sexually selected signals is what information they convey and how their honesty is maintained. Song amplitude is a performance-related signal trait that varies considerably between individuals, but this signal dimension has been neglected in past studies. I found that median song amplitude in male nightingales (Luscinia megarhynchos) and zebra finches (Taeniopygia guttata) did not vary significantly with body size or residual body mass. In contrast, I found a significant negative correlation between body size (and also residual mass) and the maximum song amplitude during interactive singing in nightingales. However, the function of these more subtle differences in song amplitude remains to be investigated. By and large, the results of this study suggest that mean song amplitude is unlikely to indicate a bird's body size or current condition (measured as residual mass).
\end{abstract}

Communicated by W.A. Searcy

H. Brumm $(\bowtie)$

AG Verhaltensbiologie, Institut für Biologie,

Freie Universität Berlin,

Berlin, Germany

e-mail: brumm@orn.mpg.de

H. Brumm

School of Biology, Institute of Behavioural and Neural Sciences,

University of St Andrews,

St Andrews, UK

Present Address:

H. Brumm

Communication and Social Behaviour Group,

Max Planck Institute for Ornithology,

Eberhard-Gwinner-Str.,

82319 Seewiesen, Germany
Keywords Animal communication · Bird song · Honest signalling Performance-related trait .

Signal evolution $\cdot$ Song amplitude

\section{Introduction}

Inter-individual variation in sexual traits is common in most organisms; thus, it is important to understand how signal variation relates to sexual selection. Bird song is one of the most widely used models in the study of sexual selection, and many studies have shown how individual variation in song characteristics affects reproductive success through mate choice and male-male competition (Catchpole and Slater 2008). However, it is often overlooked that bird song is a multifaceted behaviour that is comprised of a whole set of characters rather than a single trait, and each of these different components can be limited by specific constraints (Gil and Gahr 2002). While many studies have concentrated on song characteristics such as repertoire size, song timing and countersinging patterns, one of the most important parameters for signal transmission, song amplitude, has been neglected, although it may play an important role in encoding information relevant to sexual selection (Gil and Gahr 2002). The potential of song amplitude as an indicator of the singer's quality or condition becomes evident when we consider the great inter-individual variation in this signal trait, which has been shown in several bird species under controlled conditions in sound isolation chambers: Brumm and Todt (2002) found that song amplitude varied by more than $10 \mathrm{~dB}$ between six male nightingales (Luscinia megarhynchos), in the same number of Bengalese finches (Lonchura striata) Kobayashi and Okanoya (2003) measured an average of at least 6-dB difference between individuals, and finally a $14-\mathrm{dB}$ 
difference was found in eleven zebra finches, Taeniopygia guttata (Brumm and Slater 2006).

It is well known that frequencies of bird vocalisations can indicate body size. In a comparative study, Ryan and Brenowitz (1985) showed that bigger species tend to produce lower pitched songs. Moreover, the same negative correlation between body size and vocal pitch has also been found within species (e.g. Tubaro and Mahler 1998; Laiolo et al. 2004; Koetz et al. 2007; Geberzahn et al. unpublished data). In addition to frequency parameters, call amplitude is thought to be an honest indicator of body size in insects and, thus, to play a crucial part in sexual selection in this taxon (Simmons 1988; Gray 1997). A similar relationship between vocal intensity and body size could also have evolved in bird song. The vocal amplitude of a particular song element is determined by the air pressure in a bird's air sacs, which is built up by the abdominal expiratory muscles (Plummer and Goller 2008). As the size of these muscles is limited by the size of the bird's body, it follows that vocal amplitude could be an honest signal of body size. Despite the importance of the connexion between body size and song amplitude in birds, there is, as far as I know, only one published study on the topic. Brackenbury (1979) compared vocal sound pressure levels of several bird species and found that the bigger species did indeed tend to produce vocalisations of higher amplitude. However, trends within species have not been shown yet, although these would be much more relevant to communication and sexual selection.

When searching relationships between song amplitude and body size, it is prudent to consider that song amplitude is a flexible trait, which is individually adjusted according to the background noise (reviewed in Brumm and Slabbekoorn (2005)) and the social context (Brumm and Todt 2004; Cynx and Gell 2004; Brumm and Slater 2006; Anderson et al. 2008). Moreover, a recent experiment on courtship song in zebra finches demonstrated that birds can also regulate the amplitude of their songs depending on the distance of the targeted receiver (Brumm and Slater 2006). These causes of song amplitude variation in birds were unknown when Brackenbury (1979) published his comparative study 30 years ago. But in light of the evidence available to us today, clearly, these factors must be taken into account in all studies aiming to glean meaningful measurements of vocal power.

In the current study, I investigated the relationship between song amplitude and body size in two songbird species, the nightingale and the zebra finch, while controlling for social and environmental factors. Nightingales are territorial birds and male advertisement songs are employed in long-range communication (Naguib et al. 2008). In contrast, zebra finches are non-territorial colony breeders, and I investigated their courtship song which is used over very short distances (Zann 1996; Brumm and Slater 2006). These differences in communication distance might be important because vocal signalling of body size is of particular importance in cases in which receivers cannot assess the size of a singing male by eye. In zebra finches, females can see the courting males; but in nightingales, targeted receivers usually cannot see a singing male and, thus, are not able to visually assess its body size. Thus, a possible correlation between song amplitude and body size might be more pronounced in nightingales than in zebra finches.

\section{Materials and methods}

\section{General}

The songs of male nightingales and zebra finches were recorded on digital media (DAT or flash card) and, subsequently, morphological measurements of each male were taken. The morphologic data comprised the wing length, length of the third primary feather and the tarsus length as well as the body mass. The nightingales were studied in the wild and in a bioacoustic laboratory, whereas the zebra finches were investigated in the lab only.

To yield reliable measurements of vocal amplitude, it is crucial to consider confounding variables such as the level of masking background noise or the context of singing (solo or interactive singing, distance of targeted receiver, etc.). In the laboratory, background noise could be held constant by using acoustically shielded recording rooms, and the social context could be manipulated by the experimenter. In the field, these variables had to be controlled by careful selection of the test sites and additional measurements of ambient noise characteristics.

\section{Wild nightingales}

I used recordings from a previous study of wild nightingales and analysed post hoc the relationship between vocal amplitude and body size. The original study had been undertaken to investigate the Lombard effect in freeranging nightingales (Brumm 2004). Sound level measurements of ten solo singing males were made in the field with a CEL 314 precision (class 1) sound level metre, and subsequently, the birds were captured to measure their body size and mass. Only those birds, whose territories were not within hearing range of other nightingale territories, were used in this study. This was done to exclude the possible confounding effect of vocal interactions with neighbouring males that might have preceded the measurements. Additionally, I controlled for the Lombard effect, by including the background noise in the birds' territories in the analysis. 
On average, I analysed 29 songs per bird (range 13-57 songs). For details of the measuring protocol, see Brumm (2004). Briefly, I measured the peak sound pressure level of each song and the distance of the singing bird from the measuring microphone while controlling for the birds' orientation. This procedure allowed calculating a standardised song level that could then be compared between individuals.

\section{Captive nightingales}

I analysed the song performances of ten hand-reared nightingales, which were recorded individually in acoustic chambers in the laboratory. I recorded the spontaneous solo singing of each bird and songs sung in response to a playback simulating a rival male. Calibrated recordings were made on digital tape and the sound level of each song element was measured using Avisoft SASLab Pro (version 3.8; R. Specht, Berlin, Germany). On average, I analysed 16 solo songs (range 15-20 songs) and 13 interactive songs (range 10-20) per bird. The distance and orientation of the subject to the recording device was controlled by placing an omnidirectional microphone in the middle and above the two only perches of the test cage. Immediately after the song recordings, each male was measured and weighed. For details of the recording protocol and the data analysis see Brumm and Todt (2004) and Brumm (2006). Details of the housing are given in Brumm and Hultsch (2001).

\section{Captive zebra finches}

I analysed the courtship songs of 41 male zebra finches which were recorded individually in acoustic chambers in the laboratory. Each male was presented with a female $20 \mathrm{~cm}$ away to induce courtship. As part of their courtship display, males produce so-called directed song which is targeted at the courted female (Sossinka and Böhner 1980). Calibrated recordings of the directed songs were made with a solid state recorder and the sound level of each song element (syllable) was measured using Avisoft SASLab Pro (version 4.36). On average, I analysed 16 song motifs per bird (range 8-27 motifs). Immediately after the song recordings each male was measured and weighed. For details of the recording protocol and the data analysis, see Brumm and Slater (2006). Birefly, I used a similar array as in the experiments with captive nightingales to control the distance and orientation of the subject to the recording microphone.

\section{Statistical analyses}

To obtain one measure for body size, principal components analyses with the four initial measures (wing length, length of the third primary feather, tarsus length and mass) were conducted. For all three datasets, the Kaiser-Meyer-Olkin measure of sampling adequacy was above 0.5 , indicating that the correlation of variables was sufficient for the data reduction. For further analysis, I used the first principal component that explained the majority of the variance in the data (74\% in the wild nightingales, $76 \%$ in the captive nightingales and $51 \%$ in the zebra finches). All first components had eigenvalues higher than 1 (2.2 in the wild nightingales, 2.3 in the captive nightingales and 1.5 in the zebra finches), and all four morphological variables loaded positively on PC1. The score on the first principal component was then used as a composite measure of body size (hereafter 'body size score'). In addition to the body size score, I also considered the residual body mass (regressed on the factor scores of a principal component including the three initial body size measures but not the absolute mass). Using the residual mass, I aimed at testing whether vocal amplitude may function as an indicator of the current condition of singing males. Each dataset was evaluated with a general linear model with the song level as a dependent variable. For the lab studies, the body size score and the residual mass were included as covariates in the model. To test the wild nightingale data, I also included the level of environmental background noise as a third covariate to control for the Lombard effect. In the wild nightingales, only the maximum level of each song was recorded, but for the other datasets, I measured the sound level of each song element and calculated the median song level for each song (or song motif in the case of the zebra finches) in addition to the maximum levels. Thus, the average and the maximum vocal intensity were considered in the analysis. Non-significant covariates were removed from the models, and test statistics and $P$ values of final models are indicated in the text. In cases where models with two covariates showed a non-significant result, either of the two non-significant covariates was removed from the model and none of the resulting final models indicated a significant relationship between song amplitude on the one side and body size score and residual mass on the other.

\section{Results}

Individual differences in median vocal amplitude between males were marked in all data sets, ranging from $10 \mathrm{~dB}$ in the captive nightingales to $15 \mathrm{~dB}$ in the zebra finches (Figs. 1, 2). Similar differences between individuals were found in the peak performance, i.e. the average maximum song level (Figs. 3, 4, 5): $8-12 \mathrm{~dB}$ in the captive nightingales and $15 \mathrm{~dB}$ in the wild nightingales and zebra finches. In the following, statistical correlates of this interindividual variation in song intensity will be investigated. 
Fig. 1 Median song levels of captive nightingales $(N=10$ males) and $\mathbf{a}$ body size and $\mathbf{b}$ residual body mass $(\mathrm{dB}$ re. $20 \mu \mathrm{Pa})$. Filled circles spontaneous solo songs; open circles interactive songs in response to con-specific playback. For clarity, interquartiles are given only for the male with the most and the male with the least variation of vocal sound pressure levels
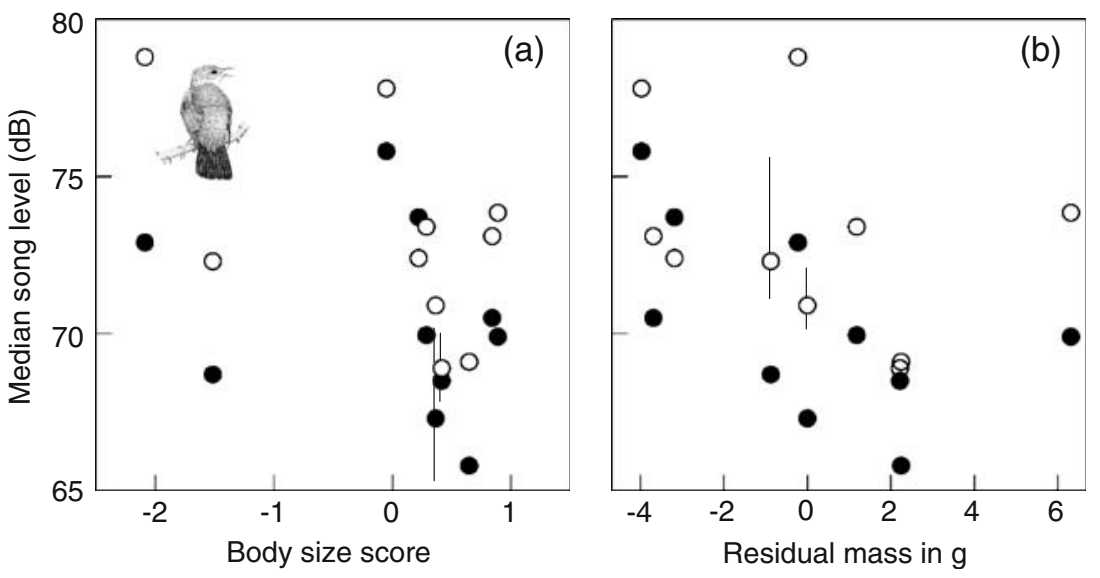

Median song amplitude

In the captive nightingales, the song amplitude variation in the solo songs could not be explained by the general linear model $\left(F_{2,7}=1.61, P=0.266\right)$, i.e. there was no significant relationship between median song intensity and body size or residual body mass. Also in the interactive songs produced in response to con-specific playback, no significant relationship between the birds' median song levels and body size or residual mass could be detected $\left(F_{2,7}=1.81, P=0.232\right)$. In addition to the absolute sound pressure levels I also investigated the relative increase in vocal peak amplitude between solo and interactive songs, i.e. the interactive capacity of the males. But again, this increase in median vocal sound pressure was not related to body size or residual mass $\left(F_{2,7}=\right.$ $1.83, P=0.229)$. The same lack of an effect was found in the non-territorial species, the zebra finch, in which the median amplitude of the males' courtship songs also did not reflect the birds' size or residual body mass $\left(F_{2,38}=0.23, P=0.794\right)$.

Maximum song amplitude

In the wild solo singing nightingales, the majority of the inter-individual variation in song amplitude could be explained by the general linear model $\left(F_{3,6}=7.51, P=\right.$ $0.019)$. However, the only significant correlate of individual song amplitude was the level of environmental noise in the birds' territories $\left(F_{1,8}=17.61, P=0.003\right.$; after removal of all non-significant covariates). No significant relationship could be found between song amplitude and body size $\left(F_{1,6}=0.68, P=0.442\right)$ or residual mass $\left(F_{1,6}=1.06, P=\right.$ $0.343)$. Like in the wild birds, the maximum solo song amplitudes of the captive nightingales did not vary significantly with their body size or residual mass $\left(F_{2,7}=\right.$ 2.08, $P=0.196)$. During interactive singing, however, when the males sang with increased vocal sound pressure levels, the variation in peak performance between males could be explained by the general linear model $\left(F_{2,7}=10.98, P=\right.$ $0.007)$. The peak sound pressure levels of interactive songs reflected both the body size $\left(F_{1,7}=10.71, P=0.014\right)$ and the residual mass of the singer $\left(F_{1,7}=6.38, P=0.040\right)$. Surprisingly, the relationship between body size and maximum song level was negative, i.e. bigger birds produced lower peak levels (Table 1). A similar negative correlation was found between residual body mass and maximum song level: lighter nightingales sang with higher maximum sound levels. In the zebra finches, the analysis of the males' peak performances yielded comparable results to the
Fig. 2 Median song levels of captive zebra finches $(N=41$ males) and a body size and $\mathbf{b}$ residual body mass ( $\mathrm{dB}$ re. $20 \mu \mathrm{Pa}$ ). For clarity, interquartiles are given only for the male with the most and the male with the least variation of vocal sound pressure levels
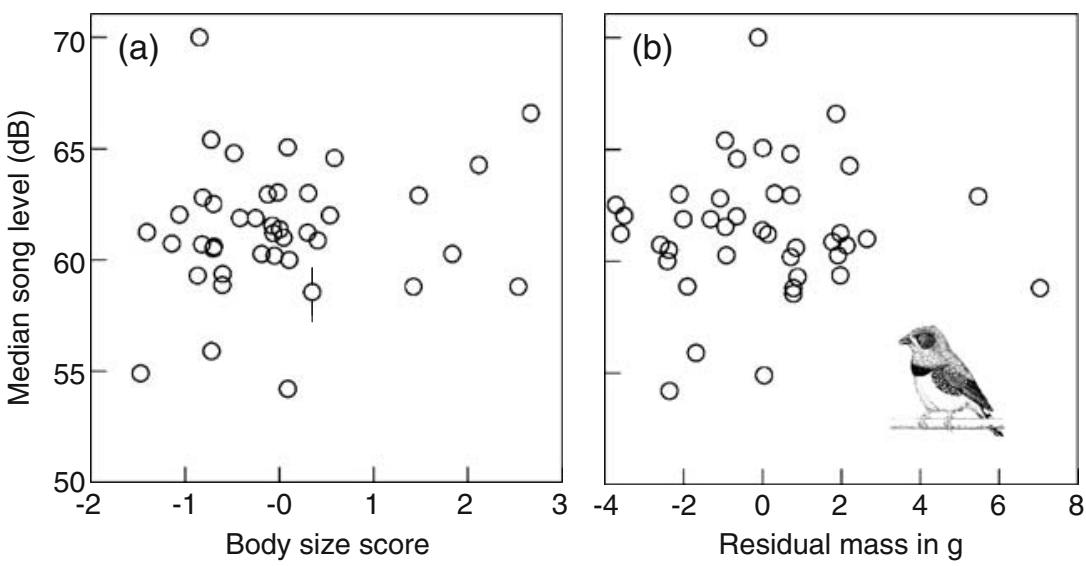
Fig. 3 Maximum song levels of wild nightingales ( $N=10$ males) and $\mathbf{a}$ body size and $\mathbf{b}$ residual body mass (dB re. $20 \mu \mathrm{Pa})$. For clarity, interquartiles are given only for the male with the most and the male with the least variation of vocal sound pressure levels
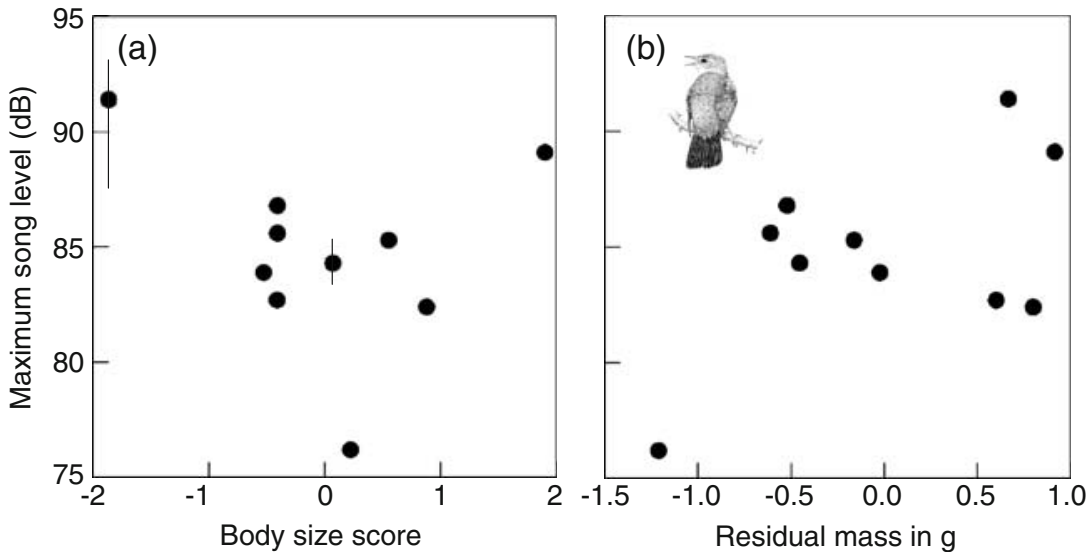

nightingales' solo songs, i.e. the variation in maximum song amplitude between males was not significantly related the birds' body size or residual mass $\left(F_{2,38}=0.395, P=0.676\right)$.

\section{Discussion}

In this study, I analysed a performance-related signal trait, song amplitude, in nightingales and zebra finches with the aim of finding out whether song amplitude could function as an indicator of body size. The calibrated song recordings revealed striking differences in vocal amplitude between individuals of each species. Differences in median vocal sound pressure levels between males ranged from $10 \mathrm{~dB}$ in captive nightingales to $15 \mathrm{~dB}$ in wild nightingales and zebra finches. This means, given the logarithmic nature of the decibel scale, that the sound pressure of the loudest males' songs was on the average three to more than five times higher than those of the softly singing birds. A similar magnitude of song level differences between males has also been reported in previous studies on songbirds (Brumm and Todt 2002; Kobayashi and Okanoya 2003; Brumm and Slater 2006). However, the striking individual variation in mean vocal amplitude found in this study was not related to the differences in body size. At the moment, it is not possible to tell whether there was generally no size effect or whether a small size effect was masked by other factors. In either case, the findings suggest that song amplitude is unlikely to function as an honest signal for body size, as it would not be very informative, if it is easily masked by other, to date unknown, factors. I also found no evidence for a significant relationship between the birds' vocal amplitude and their body mass when controlled for body size. This could be interpreted as an indication that average song amplitude does not signal a male's current condition. However, here, the current condition was assessed indirectly by measuring the males' residual mass. In future studies, a more direct approach including experimental manipulation will be helpful to further clarify the relationship between song amplitude and physical condition.

Studies in anurans and birds have shown that in some cases, vocal signals only encode reliable information about the signaller's body size when the calling animal is challenged by a rival. American toads (Bufo americanus), for instance, lower the dominant frequency of their calls when they interact vocally with a rival male, and the lowered call frequencies correlate much more strongly with the toads' body size than their higher pitched non-
Fig. 4 Maximum song levels of captive nightingales $(N=10$ males) and $\mathbf{a}$ body size and $\mathbf{b}$ residual body mass ( $\mathrm{dB}$ re. $20 \mu \mathrm{Pa})$. Filled circles spontaneous solo songs; open circles interactive songs in response to con-specific playback. For clarity, interquartiles are given only for the male with the most and the male with the least variation of vocal sound pressure levels
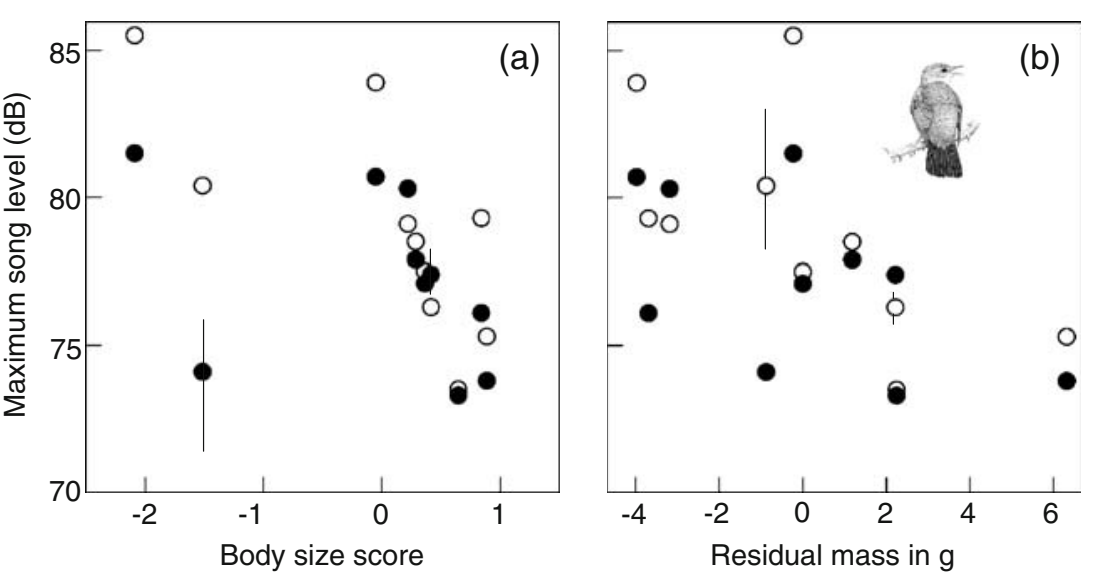
Fig. 5 Maximum song levels of captive zebra finches $(N=41$ males) and $\mathbf{a}$ body size and $\mathbf{b}$ residual body mass $(\mathrm{dB}$ re. $20 \mu \mathrm{Pa}$ ). For clarity, interquartiles are given only for the male with the most and the male with the least variation of vocal sound pressure levels
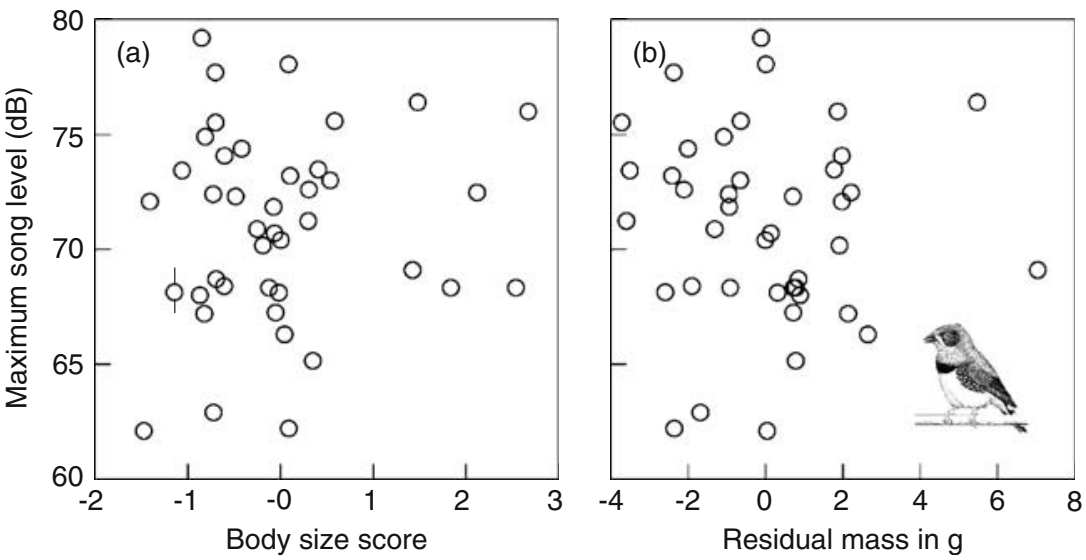

interactive calls (Howard and Young 1998). Most recently, Geberzahn et al. (unpublished data) discovered a similar phenomenon in a territorial non-passerine bird, the black coucal (Centropus grillii). This species is sex-role reversed, i.e. females defend breeding territories and advertise territory ownership by song, whereas the smaller males rarely vocalise and provide all of the parental care (Goymann et al. 2004). In their analysis of the female singing behaviour, Geberzahn et al. found no correlation between the acoustic characteristics of the female solo songs and the birds' body size. During vocal interactions, however, when the coucals were challenged by the playback of a rival female, the birds lowered the frequencies of their songs which then revealed their body size. A similar phenomenon was found in this study for the maximum amplitudes of nightingale song. Nightingales do not lower their pitch but rather increase the amplitude of their songs during challenged singing (Brumm and Todt 2004), and the results of this study show that body size and residual mass was not reflected in the sound level of solo songs but in the peak levels of interactive songs in response to con-specific playback. However, in contrast to the studies on anurans and coucals, the picture in nightingales is less clear, for a significant relationship between song amplitude and body size and mass was only found in the maximum levels but not in the median song levels. The significance of these more subtle peak differences for communication and sexual selection is unclear. If strong selection would maintain song amplitude as an indicator of body size, then one would expect overall differences in vocal sound pressure levels to vary with size or condition, which was not the case in the birds studied here. At the moment, it is not possible to tell whether the differences in peak amplitude are used to convey information. Future playback studies will help to elucidate this issue.

Interestingly enough, the correlation between maximum song amplitudes on the one side and body size and current condition on the other was negative, i.e. smaller and lighter males produced higher maximum song levels. This finding suggests that high peak levels in interactive nightingale song do not signal individual quality but rather male singing effort. The smaller males perhaps produced higher peak levels to compensate their low quality, and bigger males, on the other hand, could afford to sing with lower peak levels because they are more likely to win physical combats than small males; thus, they have less need to keep rivals at bay. This notion is in line with other recent findings on individual differences in vocal interactions in nightingales (Schmidt et al 2006, 2008). It is reasonable to assume that bigger and heavier birds are of higher quality because such individuals were found to arrive earlier in their breeding ground after migration, and they also had bigger song repertoires (Kipper et al. 2006). Moreover, male nightingales that arrive earlier on their breeding

Table 1 Correlation coefficients of song amplitude and body size, and song amplitude and residual body mass in songbirds

\begin{tabular}{|c|c|c|c|c|c|c|}
\hline \multirow[t]{2}{*}{ Species } & \multirow[t]{2}{*}{ Recording environment } & \multirow[t]{2}{*}{ Social context } & \multicolumn{2}{|c|}{ Median song amplitude } & \multicolumn{2}{|c|}{ Maximum song amplitude } \\
\hline & & & $r_{\text {body size }}$ & $r_{\text {mass }}$ & $r_{\text {body size }}$ & $r_{\text {mass }}$ \\
\hline \multirow[t]{3}{*}{ Nightingale } & Field & Solo singing & & & -0.487 & 0.586 \\
\hline & Laboratory & Solo singing & -0.276 & -0.566 & -0.376 & -0.554 \\
\hline & Laboratory & Interactive singing & -0.512 & -0.391 & -0.734 & -0.623 \\
\hline Zebra finch & Laboratory & Courtship song & 0.144 & 0.045 & 0.108 & -0.044 \\
\hline
\end{tabular}

Statistically significant relations detected by GLM procedures are indicated in bold 
grounds are more successful in attracting a mate than males returning later from their winter quarters (Amrhein et al. 2007). Schmidt et al. (2008) looked at the spatial behaviour, and the singing activity of nightingales in response to conspecific playback and found that low-quality males (i.e. males that did not succeed in attracting a mate) reacted more strongly to playbacks of simulated weak threat than did high-quality males. Possibly, the playback used in this study, simulating a rival more than $25 \mathrm{~m}$ away, was also perceived by the birds as a comparably weak threat. Thus, my finding that small males reacted more strongly (i.e. produced higher song maximum amplitudes) in response to the con-specific playback corroborates the results of Schmidt et al. (2008) on spatial behaviour and singing activity in wild nightingales.

Most interestingly, a similar negative relationship between vocal amplitude and male quality has been found in American bison, Bison bison (Wyman et al 2008). Wyman and her co-workers found no significant relation between a bull's weight and the amplitude of his rutting calls used in male-male competition. However, low quality males that sired only few offspring produced louder calls than high quality males that had more offspring. Thus, it appears that there might be a common principle of signalling intensity and male quality in birds and mammals. However, to my knowledge, the enquiry of Wyman et al. (2008) on bison and this study on song birds are the first to investigate the relationship between vocal amplitude and the size or quality of sexually displaying male mammals or birds, and considering the obvious paucity of comparative data, any conclusions about the generality of the findings are rather premature.

By and large, the findings of this study suggest that song amplitude is unlikely to function as an indicator of body size. However, the question of the significance of higher peak amplitudes of challenged singing in smaller males remains an open one. The rather surprising finding of this negative correlation opens a new avenue for future experimental investigations that eventually may help to find common principles of male-male vocal competition in birds and mammals and also to elucidate a possible common function in terms of sexual selection.

It is important to bear in mind, however, that the immense variation in mean vocal amplitude between individual birds in this study was not the result of difference $\mathrm{s}$ in body size. So, how can these striking variations in song amplitude then be explained? It is known that song learning and song performance can be affected by the past condition of birds, e.g. by developmental stress (Catchpole and Slater 2008; Holveck et al. 2008). However, a recent study on early nutritional stress in zebra finches showed that the song amplitude of adult birds is not affected by their condition during the nestling and fledgling period (Brumm et al. 2009). Possibly, the individual differences in song amplitude found in this study reflect differences in motivation. Correlating the hormone levels of birds with their vocal amplitude may help to shed light on this issue. It has been shown in many species that singing activity is closely related to androgen levels (reviewed in Ball (1999)). Moreover, Cynx et al. (2005) demonstrated that high testosterone levels lower the fundamental frequency of zebra finch songs. Perhaps also the loudness of songs is affected by androgens. In this case, vocal amplitude could be an indicator of the singer's endocrine status.

It is conceivable that song amplitude might signal a handicap such that the signal is indicative of quality because signallers of inferior quality cannot afford to bear the costs of signal production (Zahavi 1975, 1977). However, the actual costs of singing loudly still remain to be uncovered (Gil and Gahr 2002). The current picture suggests that energy expenditure plays only a very minor role (Oberweger and Goller 2001; Franz and Goller 2003; Ward et al. 2003, 2004). Most likely, the production of loud songs is primarily constrained by predation and/or social aggression. It has been shown that bird calls can attract predators (Mougeot and Bretagnolle 2000; Krams 2001; Krama and Krams 2005), although none of these studies addressed bird songs. If the songs of birds are used as a cue by predators to find their avian prey, then singing loudly may increase the predation risk since predators are more likely to detect the singing bird. Likewise, louder songs possibly increase the risk of being attacked by con-specific rivals; thus, social aggression may also constrain high song amplitudes. Dabelsteen (1981) and Todt (1981) observed that blackbirds (Turdus merula) react more aggressively to playbacks with high volume. However, Anderson et al. (2007) found that male song sparrows (Melospiza melodia) responded equally aggressively to two song variants that differed by $21 \mathrm{~dB}$. We clearly lack more quantitative data on the issue and it would be very interesting to systematically investigate social aggression as a limiting cost on the production of loud songs.

In conclusion, the individual differences in mean vocal sound pressure levels in two songbird species were not related to the size or the residual body mass of the birds. This evidence for the lack of a size effect on mean song amplitude suggests that signal intensity is very unlikely to be an indicator of body size and possibly also not of current physical condition. However, further investigations are needed to help us understand the negative correlation between peak amplitudes of interactive nightingale songs and the size and condition of the singer.

Acknowledgements I thank Nicole Geberzahn, Irmgard Teschke and the members of the Communication and Social Behaviour Group of the Max Planck Institute for Ornithology for discussions and them, as well as Bill Searcy and two anonymous referees, for helpful suggestions and comments that considerably improved the manuscript. 
Thanks also to Nigel Mann for the kind permission to use his drawings in the Figs. 1-5. The zebra finch study was carried out at the University of St Andrews - special thanks to Peter Slater for all his help and support. The nightingale studies were carried out while I was working in the Behavioural Biology Group of the Freie Universität Berlin. The Behavioural Biology Group was generally supervised by Dietmar Todt and Henrike Hultsch, and many thanks are due to them as well as to all the students and members of staff who helped handrearing birds. Also, I thank Roger Mundry and Tina Sommer for taking the body measures of the wild nightingales. While analysing the data and writing the manuscript I was supported by an Emmy Noether fellowship from the German Research Foundation (award $\mathrm{Br}$ 2309/6-1). The studies comply with the laws of the countries where they were conducted.

Open Access This article is distributed under the terms of the Creative Commons Attribution Noncommercial License which permits any noncommercial use, distribution, and reproduction in any medium, provided the original author(s) and source are credited.

\section{References}

Amrhein V, Kunc HP, Schmidt R, Naguib M (2007) Temporal patterns of territory settlement and detectability in mated and unmated nightingales Luscinia megarhynchos. Ibis 149:237-244

Anderson RC, Nowicki S, Searcy WA (2007) Soft song in song sparrows: response of males and females to an enigmatic signal. Behav Ecol Sociobiol 61:1267-1274

Anderson RC, Searcy WA, Peters S, Nowicki S (2008) Soft Song in Song Sparrows: Acoustic Structure and Implications for Signal Function. Ethology 114:662-676

Ball GF (1999) The neuroendocrine basis of seasonal changes in vocal behavior among songbirds. In: Hauser MD, Konishi M (eds) The design of animal communication. MIT Press, Cambridge, MA, pp 213-253

Brackenbury JH (1979) Power capabilities of the avian soundproducing system. J Exp Biol 78:163-166

Brumm H (2004) The impact of environmental noise on song amplitude in a territorial bird. J Anim Ecol 73:434-440

Brumm H (2006) Signalling through acoustic windows: nightingales avoid interspecific competition by short-term adjustment of song timing. J Comp Physiol A 192:1279-1285

Brumm H, Hultsch H (2001) Pattern amplitude is related to pattern imitation during the song development of nightingales. Anim Behav 61:747-754

Brumm H, Todt D (2002) Noise-dependent song amplitude regulation in a territorial songbird. Anim Behav 63:891-897

Brumm H, Todt D (2004) Male-male vocal interactions and the adjustment of song amplitude in a territorial bird. Anim Behav 67:281-286

Brumm H, Slabbekoorn H (2005) Acoustic communication in noise. Adv Study Behav 35:151-209

Brumm H, Slater PJB (2006) Animals can vary signal amplitude with receiver distance: evidence from zebra finch song. Anim Behav 71:699-705

Brumm H, Zollinger SA, Slater PJB (2009) Bird song as a signal of past condition: developmental stress, learning accuracy and vocal amplitude in zebra finches. Behav Ecol Sociobiology (in press)

Catchpole CK, Slater PJB (2008) Bird song. Biological themes and variations, 2nd edn. Cambridge University Press, Cambridge

Cynx J, Gell C (2004) Social mediation of vocal amplitude in a songbird, Taeniopygia guttata. Anim Behav 67:451-455
Cynx J, Bean NJ, Rossman I (2005) Testosterone implants alter the frequency range of zebra finch songs. Hormones and Behavior 47:446-451

Dabelsteen T (1981) The sound pressure level in the dawn song of the blackbird Turdus merula and a method for adjusting the level in experimental song to the level in natural song. Z Tierpsychol $56: 137-149$

Franz M, Goller F (2003) Respiratory patterns and oxygen consumption in singing zebra finches. J Exp Biol 206:967-978

Gil D, Gahr M (2002) The honesty of bird song: multiple constraints for multiple traits. Trends Ecol Evol 17:133-141

Goymann W, Wittenzellner A, Wingfield JC (2004) Competing females and caring males. Polyandry and sex-role reversal in African black coucals, Centropus grillii. Ethology 110:807-823

Gray DA (1997) Female house crickets, Acheta domesticus, prefer the chirps of large males. Anim Behav 54:1553-1562

Holveck M-J, Vieira de Castro AC, Lachlan RF, ten Cate C, Riebel K (2008) Accuracy of song syntax learning and singing consistency signal early condition in zebra finches. Behav Ecol 19:1267-1281

Howard RD, Young JR (1998) Individual variation in male vocal traits and female mating preferences in Bufo americanus. Anim Behav 55:1165-1179

Kipper S, Mundry R, Sommer C, Hultsch H, Todt D (2006) Song repertoire size is correlated with body measures and arrival date in common nightingales, Luscinia megarhynchos. Anim Behav $71: 211-217$

Kobayashi K, Okanoya K (2003) Context-dependent song amplitude control in Bengalese finches. Neuro Report 14:521-524

Koetz AH, Westcott DA, Congdon BC (2007) Geographical variation in song frequency and structure: the effects of vicariant isolation, habitat type and body size. Anim Behav 74:1573-1583

Krama T, Krams I (2005) Cost of mobbing call to breeding pied flycatcher, Ficedula hypoleuca. Behav Ecol 16:37-40

Krams I (2001) Communication in crested tits and the risk of predation. Anim Behav 61:1065-1068

Laiolo P, Rolando A, Delestrade A, De Sanctis A (2004) Vocalizations and morphology: interpreting the divergence among populations of Chough Pyrrhocorax pyrrhocorax and Alpine Chough $P$. graculus. Bird Study 51:248-255

Mougeot F, Bretagnolle V (2000) Predation as a cost of sexual communication in nocturnal seabirds: en experimental approach using acoustic signals. Anim Behav 60:647-656

Naguib M, Schmidt R, Sprau P, Roth T, Florcke C, Amrhein V (2008) The ecology of vocal signaling: male spacing and communication distance of different song traits in nightingales. Behav Ecol 19:1034-1040

Oberweger K, Goller F (2001) The metabolic cost of birdsong production. J Exp Biol 204:3379-3385

Plummer EM, Goller F (2008) Singing with reduced air sac volume causes uniform decrease in airflow and sound amplitude in the zebra finch. J Exp Biol 211:66-78

Ryan MJ, Brenowitz EA (1985) The role of body size, phylogeny, and ambient noise in the evolution of bird song. Am Nat 126:87-100

Schmidt R, Kunc HP, Amrhein V, Naguib M (2006) Responses to interactive playback predict future pairing success in nightingales. Anim Behav 72:1355-1362

Schmidt R, Kunc HP, Amrhein V, Naguib M (2008) Aggressive responses to broadband trills are related to subsequent pairing success in nightingales. Behav Ecol 19:635-641

Simmons LW (1988) The calling song of the field cricket, Gryllus bimaculatus (De Geer): constraints on transmission and its role in intermale competition and female choice. Anim Behav 36:380-394

Sossinka R, Böhner J (1980) Song types in the zebra finch Poephilia guttata castanotis. Z Tierpsychol 53:123-132 
Todt D (1981) On functions of vocal matching: effect of counterreplies on song post choice and singing. Z Tierpsychol 57:73-93

Tubaro PL, Mahler B (1998) Acoustic frequencies and body mass in New World doves. Condor 100:54-61

Ward S, Speakman JR, Slater PJB (2003) The energy cost of song in the canary, Serinus canaria. Anim Behav 66:893-902

Ward S, Lampe HM, Slater PJB (2004) Singing is not energetically demanding for pied flycatchers Ficedula hypoleuca. Behav Ecol $15: 477-484$
Wyman MT, Mooring MS, McCowan B, Penedo MCT, Hart LA (2008) Amplitude of bison bellows reflects male quality, physical condition and motivation. Anim Behav 76:1625-1639

Zahavi A (1975) Mate selection - a selection for a handicap. J Theor Biol 53:205-214

Zahavi A (1977) The cost of honesty (Further remarks on the handicap principle). J Theor Biol 67:603-605

Zann RA (1996) The Zebra Finch: a synthesis of field and laboratory studies. Oxford University Press, Oxford 